\title{
Competition and Quality: Evidence from the NHS Internal Market 1991-1999
}

\author{
Carol Propper \\ University of Bristol, CEPR and CMPO \\ Simon Burgess \\ University of Bristol, CEPR and CMPO
}

Denise Abraham

$C M P O$

October 2002

\begin{abstract}
Payer-driven competition has been widely advocated as a means of increasing efficiency in health care markets. The 1990s reforms to the UK health service followed this path. We examine whether competition led to better outcomes for patients, as measured by death rates after treatment following heart attacks. Using data on mortality as a measure of hospital quality and exploiting the policy change during the 1990s, we find that the relationship between competition and quality of care appears to be negative.
\end{abstract}

JEL Classifications: I1, L8, H4

Key words: Competition, health care, mortality, quality of care

\section{Address for correspondence}

Carol Propper

CMPO

Department of Economics

University of Bristol

8 Woodland Road

Bristol BS8 1TN, UK

e-mail: Carol.Propper@bristol.ac.uk.

Tel: +44 (0)1179288427. Fax: +44 (0)117928 8577 


\section{Introduction}

The introduction of competition and markets into public service has been a recurrent recent theme in reforms initiated by governments across the OECD. However, whilst the rhetoric has been strong, the evidence of the effectiveness of such reforms is somewhat weaker. The UK government has been a world leader in such reforms, introducing markets into publicly funded healthcare, education, housing amongst other services (Le Grand and Bartlett 1993). In this paper we examine the impact of the introduction of competition into a large and complex public sector organisation: the UK National Health Service. Competition between suppliers of health care in the UK was introduced in 1991, actively promoted and then later downplayed. Using data from the English NHS, we study the impact of competition on quality of healthcare. Using panel data on English hospital, which allows us to exploit variation in competition across time and space, we find that competition is associated with lower quality.

Prior to 1991, publicly funded hospital based health care in the $\mathrm{UK}^{1}$ was supplied by hospitals that received funding, based on their local populations, directly from central government. In 1991 the Conservation administration introduced competition on the supply side of the health care market by breaking the link between provision and funding. It created a set of buyers, funded by central government, who were free to purchase health care for their populations from both public and private sector suppliers. Public sector suppliers were therefore not given direct funding, but were to compete with each other, alongside a small private sector, for contracts from these public buyers. Competition was thus created by policy. Competition was actively promoted upto the mid-1990s, then somewhat downplayed. In 1997 the incoming Labour administration formally introduced policy change, stressing the role of co-operation over competition, though the separation between buyer and seller of health care remained (and remains currently).

\footnotetext{
${ }^{1}$ Publicly funded care accounts for over 85 percent of UK health care expenditure (Propper 2002).
} 
Competition in health care markets is geographically-based, as the service provided requires the user to travel to a provider of health care to receive it. By means of geography, some sellers of health care are therefore located in markets which are inherently more competitive than others. Thus the identification of the impact of competition is difficult, as location is intertwined with competitiveness. In cross-sectional analyses competition is therefore not separable from geography and the correlates of this geography, which might, for example, include the health of local populations or a history of funding. Whilst attempts can be made to control for observables, unobservables that are correlated with geography, but are not due to competition, may still affect the health care outcome in each market and their impact be incorrectly attributed to competition. While panel data can be used to control for unobservables, the slow changing nature of health care markets means that competition is often essentially fixed over a number of years.

The strategy adopted here is to identify the impact of competition from the interplay of geography and policy change. We use the fact that competition is not possible in all areas because of geography to separate hospitals into two groups: one group for whom competition was possible and one group for whom it was not. We then exploit the fact that policy changed over the period 1990s. Competition was only introduced in 1991, so did not operate until 1991. It was then first actively promoted upto 1995, somewhat downplayed in 1996 and then, after the change in administration, actively discouraged post-1997. We identify the impact of competition from the difference in quality between those hospitals for which competition was possible and those for which it was not between years when competition was actively promoted and those when it was not.

We construct a panel of all acute hospitals in England from 1991 to 1999. We measure quality in terms of death rates from emergency admissions for acute myocardial infarction (AMI). Mortality from AMI has been widely used to assess the quality of care of hospitals in the US health care market and was published as a measure of quality for UK hospitals for the first time in 1999. We find that competition appears to have decreased quality: death rates in areas subject to competition were higher than in areas not subject to competition during the first part of the 1990s but declined somewhat from 1996 onwards. The difference is not large, but we estimate the cumulative impact of 
competition on death rates to have more or less negated the fall in death rates that the whole sector experienced, probably as a result of technological innovation.

The organisation of the paper is as follows. Section 2 reviews the literature on the relationship between quality and competition. Section 3 presents the key characteristics of the NHS reforms that introduced competition, discussed the nature of competition in this 'internal market' and describes our econometric strategy. Section 4 presents the data. The results are in Section 5. The final section presents our conclusions.

\section{Empirical evidence on the impact of competition on quality in health care}

A large empirical literature has examined the impact of competition in markets for health care services. While early work focused on the consequences for prices and costs (for example, Dranove and White, 1994)), there is now a growing body of evidence on the impact of competition on quality. What appears to be emerging is rather a mixed picture. Shortell and Hughes (1988) examined the association between in-hospital mortality among Medicare patients and hospital concentration, and found a small and insignificant association between them. However, their methodology has since been criticised for their use of a fixed radius measure of geographic markets. Kessler and McClellan (2000) analysed the impact of competition on both costs and patient health outcomes. They use longitudinal Medicare claims data for the majority of elderly non-rural beneficiaries who were admitted to a hospital with Acute Myocardial Infraction from 1985-1994. They combined that with data on hospital characteristics collected by the American Hospital Association. They found that before 1991 competition led to higher costs and lower rates of adverse health outcomes but after 1990 competition led both to substantially lower costs and significantly lower rates of adverse outcomes. As of 1991, patients in the least competitive fourth of hospital markets experienced approximately 1.5 percentage points higher mortality than those in competitive areas. This might suggest that in the absence of competitive pressures between providers, hospitals take advantage of their market 
power by skimping on quality of care. Kessler and McClellan conclude from their study that whilst the welfare effects of competition in the 1980s were ambiguous, post-1990 competition was unambiguously welfare improving.

Other studies have found more mixed results. Ho and Hamilton (2000) tested the hypothesis that hospital mergers and acquisitions decrease competition and therefore reduce quality of care in the local market. They compared the quality of hospital care before and after mergers and acquisitions in California between 1992 and 1995. They found that hospital mergers had no effect on either heart attack or stroke inpatient mortality. Volpp and Waldfogel (2001) studied the impact of price competition in New Jersey on the quality of hospital care. They found that mortality from heart attacks increased following hospital rate deregulation, suggesting that more active price competition was accompanied by a decrease in quality competition. Gowrisankararan and Town (2001) estimated the effect of competition for both HMO and Medicare patients on hospital-specific mortality rates of hospitals in Southern California. They used data from the OSHPD patient discharge database to formulate risk-adjusted hospital mortality rates for AMI and pneumonia. They found that increases in the degree of competition for HMO patients decrease risk-adjusted hospital mortality rates for both pneumonia and AMI but increases in competition for Medicare enrollees are associated with increases in risk-adjusted death rates for both diagnoses. From this they concluded that, in contrast with the rest of the market, the Medicare system does not generate incentives for hospitals to compete on quality.

There is much less UK evidence on the impact of competition in health care, despite this being a central plank of the NHS reforms of the 1990s. Glennerster (1998) draws together the empirical literature in this area and concludes that little evidence exists. Exceptions include the work of Propper (1996), Propper et al. (1998), and Söderlund et al. (1997) who investigate the impact of the internal market on prices, costs and productivity. In the only large-scale study to date of the impact of competition on quality, Propper et al (2002) examined the relationship between competition and quality. As a measure of quality they use death rates after treatment following heart attacks. For each hospital they calculated a number of measures of competition, based on the number of suppliers within each hospital's catchment area. The catchment area was based on travel times, so avoids 
the problem associated with fixed radius measures or those based on administrative boundaries. The measure also measures potential rather than actual patient flows, and so avoids problems of endogeneity that may be associated with measures based on actual patient flows. An average death rate was calculated for the years 1995-7 for each hospital. Using a cross-sectional analysis we found that competition appears to be associated with lower quality (higher death rates), after controlling for patient mix and other observed characteristics of the hospital and its catchment area. The present paper builds on this work through the use of a panel, rather than a cross-section, data set of hospitals.

\section{The UK health care market}

\section{(a) Health care delivery in Britain post 1991}

In 1990 the Conservative administration introduced reforms to promote competition between health care suppliers by separating the roles of financier and supplier of health care services. Finance was still raised through general taxation, and was allocated to public agents who were responsible for purchasing health care for their populations. Two types of purchaser were created: District health authorities (DHAs), responsible for purchasing hospital services for the population in a given geographical area and General Practice Fund-Holders (GPFHs) ${ }^{2}$, primary care physicians who bought a subset of elective care for their patients. Health care services were provided by public and private suppliers, who competed for contracts with the purchasers. Public hospitals, which were originally under the control of health authorities, became separate legal entities, NHS Trusts. Contracting between purchasers and providers took place on an annual basis.

Both sets of buyers were allocated funds from central government, to be spent on hospital care. DHAs were not free to carry over surpluses from one year to the next. GPFHs were allowed to retain surpluses provided that they invested them in their practices. Patients had relatively little choice of buyer of health care. This is because, in the UK system, they

\footnotetext{
2 These were a self-selected group who cover the patients for whom they already provided primary care and are given a budget for a limited set of health services sold by providers.
} 
have little choice of family doctor. Patients whose family doctor chose to become a GPFH therefore had a purchaser that was a GPFH, while patients whose family doctors chose not to enter the scheme had a purchaser who was the DHA for the area in which they were resident.

Prices of services were available to buyers. However, there was no published data on hospital quality. Limited data on quality of care in NHS trusts was first made publicly available in $1999^{3}$. Although purchasers were given the right to buy from whichever supplier of health care they wished, in practice almost all care purchased by NHS purchasers was bought from NHS Trusts. Relatively little business went to the (limited in size and scope) private health care sector. NHS Hospitals competed with other hospitals to secure contracts from buyers. Given the importance of location in the provision of medical services, competition was primarily within geographical areas. Some of the competition took the form of sales of specific services on a cost per case basis, but most of the competition took place through annual negotiations over contracts for blocks of services, including accident and emergency services. In setting prices of these contracts, Trusts were heavily regulated. They were supposed to set price equal to average costs, to earn a certain return on assets, and were not able to carry surpluses across financial years (Propper 1995). However, in spite of these regulation, there is evidence that there is scope for competition from the location of hospitals (Appleby et al. 1994) and, that faced with very low margins between revenues and costs, Trusts had incentives to compete with each other for contracts (Propper 1996).

In summary, on the supply side, the hospital market in the UK is characterised by monopolistic competition. The cost of travel for patients, and the lack of full information on the buyers' part, means hospitals are not perfect substitutes. But few hospitals have no competitors with 30 minute travel distance (Propper, 1996). On the buyer side, buyers are not individual patients but agents (the GPFHs and the DHAs) who place contracts on behalf of patients. These agents are cash constrained, and have relatively hard budget

\footnotetext{
3 These data were 30 day in-hospital death rates (from surgery, AMI and FNF), rates of discharge following a stroke or FNF and rates of emergency readmission within 28 days of discharge from hospital. See (www.doh.gov.uk)
} 
constraints in the case of DHAs, and incentives to make savings from their budgets in the case of GPFHs. Patients are interested in quality, since they pay zero price at point of demand as care is free. Agents, on the other hand, are interested in price, and, to the extent that they are constrained by the wishes of patients, also quality. So the net effect is that agents are interested in both price and quality, though they may give considerably less weight to the latter if there is no monitoring of their behaviour (since patients can not change agents very easily and there is little scope for 'voice' $)^{\text {t. }}$.

This market can broadly be characterised as one in which the demand curve facing each hospital is downward sloping. The impact of competition in such a market has been analysed for a profit-maximising hospital whose demand is a function of price and quality by Dranove \& Satterthwaite (1998). They show the impact on quality depends on the effect of competition on the price and quality elasticities of demand. If competition increases the price elasticity alone, then the effect of competition will be to decrease quality. If competition increases the sensitivity to both price and quality, then the effect on quality is ambiguous. If competition increases the elasticity of the quality signal more than that of the price signal then quality will rise. If quality signals are measured with greater noise than price signals this will decrease the elasticity with regard to quality relative to the elasticity with regard to price. Investigation of the effect of a change in one of the parameters (say the cost of producing a unit of quality) on one choice variable will result in biased results unless the analysis takes into account the fact that both are chosen simultaneously. So the typical approach in the literature to the analysis of competition, which is a single equation estimation of costs, price or price-cost mark up on competition may give biased results. Similarly (though less commonly estimated in the literature) single equation estimates of quality on costs and competition will give biased results.

The Dranove and Sattherthwaite model assumes profit maximisation and that hospitals are free to set price and quality. While there is no profit in the UK case, surpluses can be used within year for NHS hospitals, and deficits were seen as evidence of failure on the part of hospital management 5 . But UK hospitals were regulated with respect to price.

\footnotetext{
${ }^{4}$ Kessler and McClellan's (1998) study uses data on Medicare patients where there is no price competition.

${ }^{5}$ Note profit maximisation is often put forward as a maximand even for not-for-profits in the US.
} 
Prices for each service were not set by a central government body, as in the DRG based system used for Medicare/Medicaid reimbursement used in the USA. Instead, hospitals were required to set price equal to average cost for each service. At a specialty level there is evidence that hospitals were probably not bound by this rule (Propper 1996, Propper et al 1998), as abiding by the rule is difficult to observe at this level. However, at the whole hospital level the rule probably did more or less bind, as at this level it is easy to monitor. If price equals average cost then hospitals can choose only choose quality (equivalent to cost). Quality will again be a function of both price and quality elasticities. The impact of differences in competition on quality could go either way: competition forces hospitals to cut prices and cut quality, or to improve quality. However, the simultaneity of price and quality choice is no longer an issue. To investigate the relationship between quality and competition, the appropriate reduced form model is to regress quality on competition and other factors affecting cost, where competition is hypothesised to affect both price and quality elasticities. The expected impact of competition would depend on the effect of competition on the two elasticities and the relative noise in the two signals. This is the approach taken here.

\section{(b) Our econometric approach}

Competition in health care markets is geographically defined. It therefore primarily changes only as new hospitals enter a geographical area or exit through mergers or closures. There was both merger and the establishment of new hospitals during the NHS internal market. However, there were very few entrants into the provision of accident and emergency services and most of the new hospitals that were established were the result of a split-off of a specialist unit providing care for the mentally ill and for long term care from a hospital providing a large range of services, including accident and emergency services. Similarly, there were mergers, but most of these were between specialist units and hospitals providing accident and emergency services. Therefore, to a large extent, the number of competitors in any one local market was fixed over time.

\footnotetext{
${ }^{6}$ Between 1991 and 1997 there were around major 12 reconfigurations that led to a within area reduction of one hospital providing accident and emergency services, and there were less than 5 that increased the number of such providers by one.
} 
However, competition over time was not fixed, as competition in this market was introduced by policy change. Policy change also affected the operation of the market. Competition was introduced in 1991. For the first four or so years after that the Department of Health actively promoted competition, for example, setting up structures to regulate anti-competitive behaviour ${ }^{\text {I }}$. So as the internal market developed, competition grew, though it could only grow in those markets in which there were sufficient numbers of hospitals for it to exist. But from 1995 or so there was some concern that constraints on hospital managers' behaviour limited the gains from competition (Le Grand et al 1998). In 1997, the government changed and the incoming Labour administration both built on these sentiments and wished to bring about ideological change. It therefore sought to reduce the importance of competition. It issued policy documents that stressed the promotion of co-operation over competition (Le Grand (1999), The New NHS, (1997)). While retaining the split between buyers and sellers it gave signals that competition for services was less important post-1998 than prior to 1997.

We use these changes in policy to identify the impact of competition in a data set of hospitals covering 1991- 1999. We divide hospitals into two groups: those located in markets in which competition was possible and the rest. (The specific measures of competition that we used are discussed below.) We interact this dummy variable with time. The interaction identifies the effect of competition. We also allow for hospital fixed effects. We estimate:

$m_{i t}=\alpha+\gamma t+\beta X_{i t}+\Sigma^{1999}{ }_{\tau=1991} \delta_{l} I(t=\tau) * c o m p i+\mu_{i}+\xi_{i t}$

where $m$ is the mortality from AMI for hospital $i$ at time $t, t$ is time (or a set of time dummies), $X_{i t}$ is a vector of observed hospital characteristics which vary over time (primarily case mix), $I($.) is the indicator function with value 1 if true and 0 otherwise, comp is a dummy indicating whether or not the geographical area the hospital is located can support competition, $\mu_{i}$ is a unobserved hospital effect and $\xi_{\text {it }}$ is random noise.

\footnotetext{
${ }^{7}$ In 1994 for example, the Department of Health issued a document to all Trusts and Health Authorities entitled "National Responsibilities, Local Freedoms" that set out a merger and anti-competition policy for
} 
This is essentially a difference-in-difference estimator, in which the impact of competition is derived from comparison of the death rates of hospitals in years in which competition was possible with their behaviour when it was not (1991) with the behaviour of hospitals where competition was not possible in any years. Given the discussion below, we might expect the coefficient on the time interaction to increase prior to 1997 and fall thereafter. As for all difference-in-difference estimators, we have to assume that the control group do not change to being the treated, and that any macro changes affect both groups equally. In our case, the treated and the controls are defined by geographical location and hence groups are fixed, given the limited amount of entry and exit. We allow for common macro changes through a set of fully flexible time dummies. Treatment for AMI has been subject to technological change in various OECD countries (McClellan \& Kessler (2001)).

Use of a fixed effects estimator controls for the impact of any fixed observed or unobserved factors that may be spatially associated with competition but are not due to competition. So a fixed effect approach controls for the possible correlation between location and unobservable patient health: for example, the positive correlation between inner city location and a population with poorer health. It will also control for differential investment in technology by size of hospital. Controls will still be needed for factors that may change over time.

In summary, if competition has an effect what we would expect to see is an increasing divergence between the outcomes for hospitals located in places where competition is possible and where it is not for the period 1992 to 1995 or 1996, and a decreasing divergence thereafter.

\section{Data}

\section{(a) Measurement of Quality}

NHS hospitals. 
The issue of how to measure quality in health care is long-standing and contentious. Various potential proxies for quality have been put forward, including length of stay and mortality rates. Since the United States Health Care Financing Administration began publishing hospital mortality data in 1986 a large literature has appeared on its usefulness and reliability as a measure of quality: Thomas and Hofer (1998) provide a comprehensive review. They cite evidence that poor quality care increases patients risk of mortality and that, on average the quality of care provided in hospitals identified as highmortality rate outliers is poorer than that of low-mortality rate outliers, but conclude from the existing evidence that when used as a measure of quality for individual hospitals, riskadjusted mortality rates can be seriously inaccurate. However, more recent work by McClellan and Staiger (1999) argues that suitably adjusted measures of death rate correlate well with other measures of quality.

In this paper we use death rates from acute myocardial infarction (AMI). AMI was chosen on the basis that the nature of such care is, in part, under the control of hospital management and senior physicians within the hospitals, and so outcomes are in part a choice decision of the hospital. Thomas et al (1993) model mortality risks from AMI (amongst other measures) in the US, and use a database of quality findings to determine whether the ratio of observed to expected deaths relates validly to quality. Their results provide some support for AMI as a quality indicator. AMI has also been used in recent studies of quality and competition in the US (Kessler \& McClellan 1998). To derive our death rates we use UK panel data from the hospital episode statistics (HES) database over the financial years 1991/2 through 1999/00. The measure of AMI deaths we use is a '30day' rate and measures in-hospital deaths within 30 days of emergency admission with a myocardial infarction for patients aged 50 and over ${ }^{8}$. Use of emergency admissions reduces the problem of patient selection. 30-day rates, adjusted to reduce noise, have

\footnotetext{
${ }^{8}$ Deaths occuring after transfer to another provider are credited to the provider where the patient was first admitted. Deaths following discharge are omitted. Deaths following readmission are not included.

${ }^{9}$ Many of the actions to reduce deaths from emergency admissions for AMI need to be taken soon after an attack, and so the performance of a hospital in terms of AMI reflects the performance of its accident and emergency unit. Around half the patients admitted to an acute English hospital are admitted through the accident and emergency department, so this quality measure is an important aspect of hospital quality.
} 
been shown to be good predictors of 7 day, and one-year death rates in US data (McClellan and Staiger, 1999).

One problem with using mortality as an indicator of hospital quality is that death rates are quite variable over time trust-by-trust, reflecting, in part, the issue of small denominators (hospitals may treat relatively few patients for this condition in any one year). This noise in the measures of death rates can lead to misclassification of the quality of hospitals. This is a problem that is common in the analysis of AMI death rates (McClellan and Staiger, 1999)

One indication of the amount of noise is to examine the change in ranking of hospitals over time. Table 1 takes the "best" (in the lowest $10 \%$ of death rates) hospitals in the first year of the data window (1991/2) and examines their ranking in later years 1993/4, $1995 / 6$ and 1997/8. The table shows that of hospitals ranked as best in 1991/2, 45\% are still ranked as in the best $10 \%$ in $1993 / 4,33.3 \%$ are still in this group in 1995/6 and $13.64 \%$ are still in this group in 1997/8. Only 5\% of the hospitals ranked as best in $1991 / 2$ had shifted into the worst group after 2 years, $14.29 \%$ had shifted into the worst group after four years and $4.55 \%$ had moved into this group after 6 years. Mean mortality difference between these hospitals and all others was negative and significant in 1993/4 and 1997/8. McClellan and Staiger (1999) present this analysis for a sample of nearly 4000 hospitals in the USA. Our data exhibit less variability than the US data. For the US data, hospitals in the best ranking were, two years later, nearly as likely to be ranked amongst the worst (14.7\%) as amongst the best (16.7\%). Average mortality amongst these hospitals was in fact higher than the average of all others after 2 years.

McClellan and Staiger (1999) suggest a method of filtering out the noise in annual estimates. They have at their disposal 10 years of data at patient level. Using their 'filtered' estimates they find that $52 \%$ of hospitals ranked in the best group were still ranked in the top decile two years later, and less than one percent were ranked in the bottom decile. Clearly, our data lie somewhere between the US unadjusted data and the filtered data. This may be due to the fact that the hospitals in our data set are on average larger than those in the USA. The mean annual number of admissions for AMI in our data set is 380, while in the US sample used in McClellan and Staiger the average hospital 
admits between 50-60 AMI patients per year.

The method we use to reduce the noise inherent in our annual death rate measures is in similar spirit to the shrinkage technique proposed originally by Stein (1955). We obtain a 'shrunken' estimate for hospital $j$ in year $t$ by calculating a weighted average of the hospitals own observed death rate in year $t\left(\mathrm{M}_{j t}\right)$ and the mean of the other hospitals in the sample in year $t(\mathrm{M} t)$. The shrunken death rate estimator can be expressed as follows:

$$
\widehat{M}_{j t}=M_{j t} S_{j}+M_{t}\left(1-S_{j}\right)
$$

The shrinkage weight for hospital $j\left(\mathrm{~S}_{j}\right)$ reflects the level of reliability in hospital $j$ 's point

estimate. It is equal to $\sigma^{\mathrm{b}} /\left(\sigma_{\mathrm{j}}^{\mathrm{w}}+\sigma^{\mathrm{b}}\right)$, where $\sigma^{\mathrm{b}}$ is the between group (hospital) variance and $\sigma_{j}{ }^{\mathrm{w}}$ is the within group (hospital) variance. The less noisy the death rate series for a given hospital the lower the proportion of total variance that is within hospital variance and thus the larger is the shrinkage weight for that hospital. The larger the shrinkage weight the closer is the estimate to the hospitals observed death rate. When the within hospital variance is relatively high (e.g. when the hospital admits few patients) and when then there is less variation in death rates across hospitals the shrinkage weight for hospital $j$ will be close to zero. The smaller this coefficient the more weight is given to the mean mortality rate across hospitals - and hence the greater the "shrinkage" towards the overall mean (an estimate in which there is more confidence).

\section{(b) Measures of competition}

Our measures of competition are geographically based since treatment for AMI requires the physical presence of the patient at the hospital. These are calculated only once for each hospital, as there is relatively little change in the number of hospitals or the population of an area in the nine-year window. To derive these requires a definition of each hospital's 'catchment' area. In general it is argued that administrative boundaries do not measure catchment areas well (e.g. Kessler and McClellan, 1998), and the obvious administrative area in the UK case, the health authority, is also likely to be a poor candidate, especially in more competitive areas. The reforms were introduced in part because health authority boundaries were not co-terminous with patient flows, leading to 
cross-boundary flows that were not easily remunerated in the pre-reform NHS. Instead, we use a definition of catchment area that reflects patient costs. Any measure that is based on actual hospital choices may produce biased estimators: unobservable hospital heterogeneity in hospital quality may affect individual choice and may also affect the mortality of the hospitals. For this reason, the measures used in our analysis are based on potential, rather than actual, patient travel times to each hospital.

In contrast with data used in recent US analyses, we do not have access to individual patient addresses. Instead, we assume that individuals are potential patients of any trust that they are close to. To be specific, we draw a boundary around each trust that defines the area within 30 minutes drive from the trust. Clearly, the choice of 30 minutes is arbitrary. This boundary delineates the 'service area' or catchment area of the trust. The details of the construction of this are as follows. We extracted a postcode for each Trust from NHS Yearbooks, and then converted this to a map grid reference using Postzon software. This allows us to locate each trust on an electronic map; we then superimpose on that the road network 1 . Using assumed speeds for three different road types, we can locate a set of points exactly 30 minutes drive time away. Joining these up gives us a catchment area for each hospital. Finally, we superimpose these with the small electoral area boundaries (wards). These are 1991 census wards, of which there are approximately 8000 , compared to some 250 trusts. We tag a ward as belonging to the service area of a particular trust if any portion of the ward falls within the 30-minute zone.

The simplest measure of competition is the number of trusts located in the catchment area of hospital $j$ :

$$
C_{j}^{0}=T_{j}
$$

This measures the number of potential competitors that $j$ faces, but doesn't take into account the population to be served by the hospital. The smaller this population for a given number of trusts, the more spare capacity and so the larger the potential amount of competition. To allow for this, we normalise the number of trusts in an area by the population of the area $\left(P_{j}\right)$ 


$$
C_{j}^{1}=T_{j} / P_{j}
$$

The higher this is, the more competitive the environment.

Our third measure of competition measures the extent to which the population of a hospital's catchment area can choose between different hospitals. First, we determine the population of the wards that fall into each hospital's catchment area and the number of trusts each ward population has within a 30-minute radius. Then for each trust $j$ we can calculate the share of the total population in all the wards it serves that have a choice between different numbers of hospitals. That is, for each particular hospital we calculate the proportion of its catchment area population that have access to only that hospital, or that can access only 2 hospitals etc. This is measure $\mathrm{C}^{2}$. This is not a single variable but a distribution, which we can cut in a number of different ways in our empirical analysis. Note that, unlike measure $\mathrm{C}^{1}$, this second measure is independent of the size of the population in the catchment area.

The measures are obviously related, but are by no means identical. Figure 1 presents histograms of the distribution of the three measures of competition over hospitals in the sample. Figure 1(a) presents measure $C^{0}$, Figure 1(b) presents $C^{1}$, and Figures 1(c)-(e) present three cuts of $\mathrm{C}^{2}$. The first cut is the proportion of the hospital's catchment area population that can reach at least three hospitals. The second is the proportion that can reach at least 6 hospitals and the third is the proportion that can reach at least 11 hospitals.

The measures show quite a range in competitiveness of hospital market. The histogram of $\mathrm{C}^{0}$ shows the number of hospitals in each hospital's catchment area. There is a relatively large proportion of hospitals that have fewer than $\mathbf{x}$ competitors in their service area, while a small number of trusts have lots of competitors, with the largest number being 46. The distribution of $\mathrm{C}^{1}$ shows a similar pattern to $\mathrm{C}^{0}$, but also shows that the effect of standardising the number of competitors in the catchment area by the population of the areas is to shift more weight to the bottom end of the distribution. Fig 1(c) illustrates that travel times are such that lack of potential choice is relatively rare: for the

\footnotetext{
${ }^{10}$ Using Arcview software.
} 
vast majority of hospitals, the proportion of their service area population that can reach 3 or more hospitals (the first cut of $\mathrm{C}^{2}$ ) is close to 1 . This distribution is also slightly bimodal. Figs 1(d) shows the distribution of the second cut of $\mathrm{C}^{2}$. This is clearly bimodal: there is a large group of hospitals that have a very high proportion of their service area population able to reach at least 6 trusts whilst there is also a fairly large group that have a very low proportion. Fig 1(e) shows a very similar distribution for the third cut of $\mathrm{C}^{2}$. It is even more bimodal, and has more weight in the lower tail of the distribution. The proportion of a hospital's catchment area population that can reach 11 or more hospitals is generally either close to zero or close to 1.

In table $\mathrm{X} 0$ we categorise these competition measures into 3 quantiles and present the correlations between them. There is a relatively high correlation between all the measures with the exception of $C^{1}$. The effect of the normalisation of $C^{1}$ by the service area population is that there are some areas that have both a low number of hospitals and a low population and therefore fall into the upper two thirds of the distribution of $\mathrm{C}^{1}$. This reduces the correlation between this and the other measures of competition.

\section{(c) Controls}

We exploit the panel nature of our data and estimate fixed effects models. Therefore several of the controls that we would want in a cross sectional analysis get absorbed into the fixed effect. Our time-varying controls are controls for case-mix (we do not have data on patient co-morbidity so use the distribution of AMI admissions by age and by gender) and controls for size/throughput (measured by the number of total admissions, and the number of emergency AMI admissions). Higher volumes of patients have been shown to be associated with better success rates. To compare our work to our previous crosssectional analyses (Propper et al 2002) we can examine the relationship between the estimated fixed effects and observed, fixed, characteristics of the hospital and its catchment area. The fixed characteristics we measure include dummies for whether the trust is a teaching hospital, or a heart specialist, or is in London, region, and proxies for population health of the catchment area. Teaching hospitals are often thought to have better facilities but also to attract harder cases. The London dummy is to ensure that any 
special features of hospitals in the capital do not drive our results. The definition of region is the geographically based administrative region of the NHS. ${ }^{-1}$ As controls for the severity of the potential population of the hospital we use area (1991 Census ward) characteristics that might affect the general level of health of the potential patients of the trust. For each ward, we have all cause mortality and AMI mortality (both split by age and gender), and the proportion of the population with long-term limiting illness. We have demographic data on the age and gender structure of the population. We also have data on unemployment and inactivity rates (by gender) and measures of wealth or deprivation such as proportion of homes owner-occupied, or proportion of homes without indoor bathrooms. These measures of deprivation are quite collinear, and in our analyses we use only a subset of these. 12

Table A1 provides details of the dependent variable, the measures of competition and the controls. Our data set contains 252 hospitals: this is the population of all English hospitals that provide any acute service. Where a trust admits less than 10 AMI cases in any one year we exclude this datapoint from the analysis. We do this as using such small denominators in the calculation of the death rate means that very few deaths can create a high overall rate. After exclusions because of missing controls and small admissions the sample size is 226 hospitals. Details of all data sources are provided in table A2.

\section{Results}

\section{(a) The effect of competition}

Figure 2 presents the aggregate AMI death rate over the 8 years of the sample. This shows a clear downward trend in death rates in our data. This downward trend is evident in the data for a number of OECD countries and has been attributed to the adoption of

\footnotetext{
11 These are not fully coterminous with, but overlap considerably with, other geographically-based definitions of English regions.

12 There are several studies of England and the UK which show strong relationships between measures of mortality and deprivation at a local level (e.g. Eames et al, 1993, Ben-Schlomo et al, 1996, Drever and Whitehead, 1995).
} 
new technology in the treatment of AMI (McClellan \& Kessler, 2001). The trend in figure 2 is not dissimilar to the trend for Scotland during the 1990s.

Figure 3 splits the hospitals in the sample on the basis of three quantiles of competition measure $\mathrm{C}_{1}$. Those hospitals in the bottom third of this distribution face little/no competition throughout the whole of the period 1991-99 (for example, 18\% are monopolies) while the rest faced some. The figure plots the average death rate by each quantile for 1991-1999. The results show a more or less continuous decline in death rates for hospitals in the least competitive markets. Death rates for those hospitals in the more competitive markets do not fall much up to 1995 and then fall more sharply from then onwards, with a blip in 1998. The rates for the two higher competition groups are quite similar. So these raw data show first a divergence between death rates of hospitals facing little/no competition and those facing some (those in the top two thirds of the distribution) and a pattern in this divergence which corresponds to the policy introduction of competition, its promotion upto the mid 1990s and its reduction in importance thereafter.

Table 3 presents estimates of the difference in death rates between non-competitive and competitive hospitals. Competition is defined in three ways: as dummy variables based on measure $\mathrm{C}^{1}$, based on the total number of hospitals in a service area, and based on the measure $C^{2}$. In columns 1 and 2 hospitals are classified as facing competition if they are in the top two thirds of $\mathrm{C}^{1}$ and as facing no competition otherwise. Column 1 uses all hospitals, column 2 omits those hospitals, which have no competitors in their catchment area but have small populations and so fall into the top 66 percentile of competition measure $C^{1}$. In column three all hospitals which have at least one other hospital in their catchment area are classified as facing competition. Columns 4-6 are based on competition measure $\mathrm{C}^{2}$, with the number of hospitals classified as facing competition falling from column 4 to 6 . In column 4 hospitals for which 100 percent of their catchment areas population can reach 3 or more hospitals are classified as facing competition. In column 5 hospitals for which 100 percent of their catchment areas population can reach 6 or more hospitals are classified as facing competition. In column 6

\footnotetext{
${ }^{13}$ See McGuire and Windmeijer (2002).
} 
hospitals for which 100 percent of their catchment areas population can reach 11 or more hospitals are classified as facing competition. The proportion of hospitals classified as facing competition is 44 percent of the sample in column 4, 21 percent in column 5 and 7 percent in column 6 .

Equation (1) is estimated using these different definitions of competition. The impact of competition is identified from the interaction of the year dummies with the competition dummy. The omitted year is 1991, the year of the introduction of the competition policy. Our prior is an increase in the impact of competition upto the mid-1990s and a fall thereafter. The results, with the single exception of column (4), support this prior. The coefficients on the interactions of year dummies with competition rise from 1992 to plateau in 1995 and 1996, then fall in 1997, rise in most of the columns in 1998 and then fall in 1999. They are generally not significantly different from zero in the early one or two years of the operation of the competition policy, or in 1997 and 1999, when the policy was beginning to be reversed, but are well defined for the mid-1990s and sometimes for 1998. The blip in 1998 is present in most but not all of the columns. A clear time trend is present in all columns and is very similar across all definitions of competition.

The estimates also show a clear pattern across the different measures of competition/no competition. The estimates of columns (1), (2) and (5) are broadly the same. The estimates of column (3) are smaller. In this column, no-competition is defined as the presence of only one seller in a market, whereas the definitions used in the other columns include hospitals with more competitors in the group defined as facing no competition. It may be the case that monopoly itself is associated with higher death rates. In contrast, the estimates of column (6) are approximately twice the size of those in columns (1), (2) and (5). In this column, we define competition as existing only if patients can reach many hospitals; i.e. there are many potential sellers in the market. Clearly, the effect of this high competition on death rates is large.

The exception to these results, column (4), is probably due to the definition of competition. Having a catchment area in which the all population can reach 3 or more trusts within 30 minutes does not appear to distinguish between the competitive and the 
non-competitive: the definition splits the sample into two more or less equal size groups and so does not allow us to identify either monopolies or those hospitals where a great deal of competition is possible (policy permitting).

Figure 4 plots the coefficients on the time*competition interactions and their standard errors from all the estimates in Table 3. This shows that the divergence in death rates between hospitals facing some- and no-competition reaches a plateau in the mid 1990s, then falls, rises in 1998 and then falls in 1999. With the exception of the rise in 1998 the pattern supports our hypothesis that the impact of competition, where it could operate for geographic reasons, would increase and then operate more weakly after the election of the Labour government in 1997.

The fixed characteristics of hospitals that are associated with high death rates can be examined by regressing the fixed effects from the estimates in Table 3 (the $\mu_{\mathrm{i}}$ in equation (1)) against fixed characteristics of the hospitals, including their catchment areas. These results (not presented here $)^{14}$ show that hospitals with higher numbers of beds and which are heart specialists have lower death rates, that there are no differences between teaching and non-teaching hospitals, that there are regional differences in the hospital fixed effects and there is some indication that hospitals located in areas of higher social deprivation have lower death rates. These differences are the same as those found in the crosssectional analyses of AMI death rates presented in Propper et al (2002).

\section{(b) The impact of case mix}

The results in Table 3 control for case mix differences which are fixed over time, but do not control for changes in case mix. If case-mix changes as a response to competition, the differences in death rates might be due in part to differences in patient type and our finding that death rates are higher in more competitive areas may therefore be the result of hospitals which are in located in low competition markets receiving fewer more ill patients. While this may occur for elective patients, it seems less likely to occur in the case of emergency AMI admissions. Hospitals that face few competitors would seem to

\footnotetext{
${ }^{14}$ Results available from the authors on request.
} 
be less, rather than more, able to refuse patients. In our sample, hospitals that have higher admissions for AMI are more likely to be low competition, suggesting that this, in fact, is the case so perhaps case mix is not a major issue 15 . However, while risk-adjusted death rates are not yet published for the UK, to have some control for case mix, the model was re-estimated including controls for the proportion of patients admitted each year in 36 age-gender groups. ${ }^{16}$ Inclusion of these controls slightly decreased the standard errors on some of the competition*time interactions, but the controls themselves were not statistically significant.

These controls are admittedly somewhat crude. While we cannot make more detailed adjustment, one test of robustness of the results is to estimate the model on one particular age group only. Table 4 presents the estimates of model (1) for individuals aged 50-69, males and females separately. These two groups account for a high proportion of all AMI admissions: males are $29 \%$ and females are $11 \%$ of total AMI admissions. The measure of competition used is that from column 2 of table 3. The table shows that the results for males are very similar to the overall results: competition appears to raise death rates and there is a significant downward time trend. Given the importance of this group to total AMI admissions, this is perhaps not surprising. The results for female are rather different: while the downward time trend exists there appears to be no impact of competition.

\section{(c) The effect of size}

Table 3 includes a control for activity, total hospital admissions. This is weakly associated with lower death rates, but the coefficient is not well defined. We found no impact of AMI activity or of hospital size (number of beds). This contrasts with a literature that suggests practice makes perfect in medical care, but is a finding that is similar to that found in the earlier analyses of English data in Propper et al (2002). 17

\footnotetext{
15 The mean number of AMI admissions for the 'no competition' group is 453, whilst the mean for all others is 342 .

${ }^{16}$ Male and female AMI admissions are broken down into 5-year age bands (age 0-4 through to age 80-84, with an additional band for the 85 plus age group)

${ }^{17}$ Given our estimates use panel data, average size/activity is differenced out, and we might not expect much of an impact from year-on-year fluctuations in activity.
} 
However, it is possible that hospitals with different levels of activity or size respond differently to competition. To explore this, we split the sample on the basis of average bed size (a measure of size and to some extent also activity), of average AMI admissions and of average total admissions 18 . The measure of competition used is that of column 2 of table 3. The results, in table 5, show that, while not necessarily well defined, the impact of competition on death rates appears to be less in hospitals with more activity. There is also some indication that the general fall in death rates is lower in smaller hospitals: for all measures of size the coefficient on time is smaller in magnitude for the smaller hospitals, though the coefficients are not statistically different. The final column of table 5 uses the available data to investigate whether the impact of competition differed across hospitals facing differential operating pressures. As a measure of such pressure we use the ratio of total admissions to total number of doctors in a hospital. Hospitals with a high ratio might be viewed as being under greater pressure. Interestingly, and perhaps contrary to expectations, the results indicate that it is the group of hospitals who are under less pressure who have a stronger association of higher death rates with competition.

\section{Conclusion}

The introduction of payer-driven competition has been one of the primary forms of health care reform advocated in the last two decades. It was introduced in the UK in 1991, on the basis of relatively little evidence on the impact of such competition on either costs or quality. The emerging evidence from other health care systems suggests a mixed impact of competition on quality and the only study to date for the UK, which uses cross sectional data, suggests a small negative effect. The present paper uses data on a panel of all acute hospitals in the English NHS from 1991 to 1999. Use of panel data allows us to control for observed and unobserved heterogeneity between hospitals, which is important

\footnotetext{
${ }^{18}$ Bed size is the number of average available hospital beds in 1996, whilst average AMI admissions and average total admissions are defined as the mean number across years 1991-1999.
} 
as hospitals differ in the quality of their staffing, plant and case-mix in ways that are difficult to capture in observed data. Competition in this market is geographically based, and in any one market there is relatively little entry and exit over the period. However, we exploit important changes in policy to identify the impact of competition. Competition was introduced in 1991, and was then encouraged by the government upto the middle 1990s. In 1997 the incoming Labour administration changed this policy and actively encouraged co-operation rather than competition. These policy changes meant that in 1991, regardless of the configuration of the local market, no competition was possible. Thereafter, competition was possible, but only in local markets in which there were sufficient numbers of suppliers. Post 1997, although competition was possible, it was actively discouraged. Hence any impact of competition on quality should begin in 1992, increase upto the mid-1990s and then tail off thereafter.

Using this identification strategy, we use data on hospital death rates from acute myocardial infarction (AMI) within 30 days of admission to hospital as a measure of quality of care. This measure has been widely used in previous studies. We use geographical information to identify a hospital's catchment area, defined in terms of travel times for potential patients. This information allows us to calculate several geographically based measures of competition, which are all based on potential, rather than actual, patient travel. This allows us to overcome criticisms of earlier studies which used measured based on either actual patient flows or administrative boundaries.

We find the impact of competition is to reduce quality. Hospitals located in more competitive areas have higher death rates during the period. The difference between those hospitals subject to competition and those not increased from 1992 to the mid-1990s and then fell (except for an unexplained blip in 1998). The estimated effect of competition is robust to different measures of competition and hospital volume. The point estimates for 1995 (the date at which competition was at its height) are of the order of a third of a standard deviation of the mean death rate for the whole sample. But this figure somewhat masks the full impact of competition. Death rates were higher in competitive areas in most years between 1992 and 1999. Cumulated over the entire period, the impact of competition in raising death rates more than matched the fall in death rates due to 
technological innovation. In other words, the negative impact of competition in the more competitive areas more than offsets the positive impact of technological change.

However, our results do not mean that the introduction of competition had no benefits. Under the pricing regulations in force in the UK internal market, a fall in quality should be matched by a fall in costs and research has shown that competition in the UK health care market has been associated with lower costs and prices. And we have not found that all quality has fallen: our results show that the quality of one service, treatment for AMI, has fallen where competitive forces are high. While AMI death rates are widely used as a measure of hospital quality, hospitals are multi-product firms. AMI is part of accident and emergency services. These services need to be provided on a local basis. Given this, it is possible that hospitals in the UK competed by simultaneously lowering quality for services for which demand elasticity was low whilst raising quality where demand elasticity was higher. If this was the case, then our finding that competition is associated with lower quality for AMI is not necessarily incompatible with competition raising overall quality. There are no published data with which to investigate this hypothesis so this remains to be investigated in further research. 


\section{Acknowledgements}

We are grateful to the MRC funded Health Services Research collaboration for access to the data on AMI death rates, and to Davidson Ho for all his help in providing the data. We are grateful to the Leverhulme Trust for funding. All errors are our responsibility.

\section{References}

Appleby J., Smith P., Ranade W., Little V., \& Robinson R. (1994) Monitoring managed competition. In Le Grand J., Robinson R. (Eds.), Evaluating the NHS Reforms. London: King's Fund Institute, 24-53

Ben-Shlomo Y., White, I.R. \& Marmot, M.G., (1996) Does the variation in the socioeconomic characteristics of an area affect mortality? British Medical Journal 312, 1013-1014

Dranove, D., \& Satterthwaite, M.A., (1998) The Industrial Organisation of Health Care markets, Handbook of Health Economics.

Dranove, D., \& White, W.D., (1994) Recent Theory and Evidence on Competition in Hospital Markets, Journal of Economics and Management Strategy, 3, 169-209.

Drever, F. \& Whitehead, M. (1995) Mortality in regions and local authority districts in the 1990's: exploring the relationship with deprivation. Population Trends, 82, $19-26$

Eames, M., Ben-Shlomo Y., \& Marmot, M.G., (1993) Social deprivation and premature mortality: regional comparison across England, British Medical Journal, 307, 1097-102

Glennerster, H. (1998) Competition and quality in health care: the UK experience, International Journal of Quality in Health Care, 10 (5), 403-410.

Gowrisankaran, G., \& Town, R. (2001) Competition, Payers and Hospital Quality, unpublished mimeo. 
Hamilton, B.H, \& Ho, V. (2000) Hospital Mergers and Acquisitions: Does Market Consolidation Harm Patents?, Journal of Health Economics, 19(5):767-791

Kessler, D., \& McClellan, M. (2000) Is Hospital Competition Socially Wasteful?, Quarterly Journal of Economics, 115(2): 577-615

Kessler, D., \& McClellan, M. (May/June 2001) Technological Change around the world: Evidence From Heart Attack Care, Health affairs

Le Grand, J., Bartlett, W. (1993) Quasi-markets and Social Policy, Macmillan

Le Grand, J., Mays, N., \& Mulligan, J. (1998) Learning from the NHS Internal Market: A review of the evidence. London: Kings Fund

Le Grand, J. (1999) Competition, Cooperation, or control? Tales from the British National Health Service, Health Affairs 18, pg27-37

McClellan, M. and D. Staiger (1999) The quality of health care providers. NBER Working Paper 7327.

McGuire, A, \& Windmeijer, F, (2002). Regulation and the Diffusion of Health Care Technology, unpublished mimeo, LSE Health \& Social Care.

Propper, C. (1995) Regulatory reform of the NHS internal market. Health Economics, 4, $71-83$

Propper, C. (1996) Market Structure and Prices: The Responses of Hospitals in the UK National Health Service to Competition, Journal of Public Economics, 61, 307335

Propper, C., Wilson, D., \& Söderlund, N. (1998) The Effects of Regulation and Competition in the NHS Internal Market: The Case of GP Fundholder Prices, Journal of Health Economics, 17 (6), 645-674

Propper, C,. Burgess, B., Green, K. (2002) Does Competition Between Hospitals Improve the Quality of Care? Hospital Death Rates and the NHS Internal Market, unpublished mimeo, University of Bristol, CEPR \& CMPO 
Shortell, M., \& Hughes, E. (1988) The Effects of Regulation, Competition, and Ownership on Mortality rates among Hospital Inpatients, The New England Journal of Medicine, 318, 1100-1107.

Söderlund, N., Csaba, I., Gray, A., Milne,.R., \& Raftery, J. (1997) Impact of the NHS reforms on English hospital productivity: an analysis of the first three years, British Medical Journal, 315, 1126-1129.

Stein, C.(1995), Inadmissibility of the usual estimator for the mean multivariate normal population. Proceedings of the Third Berkeley Symposium on Mathematical Statistics and Probablity, 1, 197-206

Thomas, J.W., \& Hofer, T. (1998) Research Evidence on the Validity of Risk-Adjusted Mortality Rate as a measure of Hospital Quality of Care, Medical Care, 55, 4.

Thomas, J.W., Holloway, J.J., \& Guire, K.E. (1993) Validating Risk-Adjusted Mortality as an Indicator for Quality of Care, Inquiry, 30, 6-22

Volp, K. \& J. Waldfogel (2001) Competition and the quality of hospital care: Heart Attack Mortality After the Onset of Price Competition in New Jersey, unpublished mimeo 
Table A1: Variable summary

\begin{tabular}{|c|c|c|c|c|c|}
\hline Variable name & Variable Details & Mean (s.e) & Median & Min & Max \\
\hline Shrunken AMI Death Rate & $\begin{array}{l}\text { Weighted AMI emergency death rate. Weights are } \\
\text { \# emergency admissions. Source: Table A2 }\end{array}$ & $0.212(0.064)$ & 0.207 & 0.026 & 1 \\
\hline Shrunken FNF Death Rate & $\begin{array}{l}\text { Weighted FNF emergency death rate. Weights are } \\
\text { \# emergency admissions. Source: Table A1 }\end{array}$ & $0.076(0.028)$ & 0.073 & 0 & 0.185 \\
\hline Competition Measure 1 & $\begin{array}{l}\text { (Number of trusts in catchment area/population of } \\
\text { catchment area) } \times 100,000\end{array}$ & 0.538 & 0.519 & 0.240 & 1.724 \\
\hline Competition Measure 2 & $\begin{array}{l}\text { Percentage of population in trust catchment area } \\
\text { who can reach } 3 \text { or more trusts } \\
\text { Percentage of population in trust catchment area } \\
\text { who can reach } 6 \text { or more trusts } \\
\text { Percentage of population in trust catchment area } \\
\text { who can reach } 11 \text { or more trusts }\end{array}$ & $\begin{array}{l}0.815(0.331) \\
0.640(0.405) \\
0.459(0.418)\end{array}$ & $\begin{array}{l}0.997 \\
0.877 \\
0.445\end{array}$ & $\begin{array}{l}0 \\
0 \\
0\end{array}$ & $\begin{array}{l}1 \\
1 \\
1\end{array}$ \\
\hline $\begin{array}{l}\% \text { male residents with long-term } \\
\text { limiting illness }\end{array}$ & & $11.928(2.137)$ & 11.756 & 7.838 & 17.021 \\
\hline$\%$ households owner occupied & & $67.258(6.370)$ & 67.752 & 53.861 & 79.038 \\
\hline $\begin{array}{l}\text { \% economically active males } \\
\text { aged } 16+\text { unemployed in } \\
\text { catchment area }\end{array}$ & & $11.072(2.885)$ & 11.182 & 5.214 & 18.359 \\
\hline Hospital is heart specialist & Hospital coded as heart specialist in $1996 / 7$. & $0.080(0.271)$ & 0 & 0 & 1 \\
\hline Teaching hospital & Hospital coded as teaching hospital in 1996/7. & $0.119(0.325)$ & 0 & 0 & 1 \\
\hline London hospital & Hospital located in London. & $0.124(0.330)$ & 0 & 0 & 1 \\
\hline Total hospital admissions & & $42618.67(211146.99)$ & 39520 & 50 & 130986 \\
\hline $\begin{array}{l}\text { Total AMI emergency } \\
\text { admissions }\end{array}$ & & $407.972(213.354)$ & 380 & 1 & 1357 \\
\hline total admissions/no. of doctors & & $210.364(89.429)$ & 206.853 & 23.139 & 1223.533 \\
\hline Total beds in hospital (1996) & & $651.938(288.34)$ & 625 & 74 & 1564 \\
\hline
\end{tabular}




\section{Data Appendix}

Table A2: Data Sources

\begin{tabular}{|l|l|l|l|}
\hline Variable & Year & Source & Level provided \\
\hline AMI deaths \& cases & & & NHS Trust \\
Total admissions & $91 / 92-99 / 00$ & HES database & Finance and accounting (CIPFA) \\
\hline Speciality and teaching dummies & & Department of Health & NHS Trust \\
\hline Hospital beds & $1996 / 7$ & Hospital Year Book Trust & NHS Trust \\
\hline Region & $1996 / 7$ & 1991 Census of Population & Electoral Ward (Aggregated to trust \\
level using Arcview)
\end{tabular}

* Detailed technical Annex of data set construction also available from authors. 

Figure 1: Histograms of competition measures
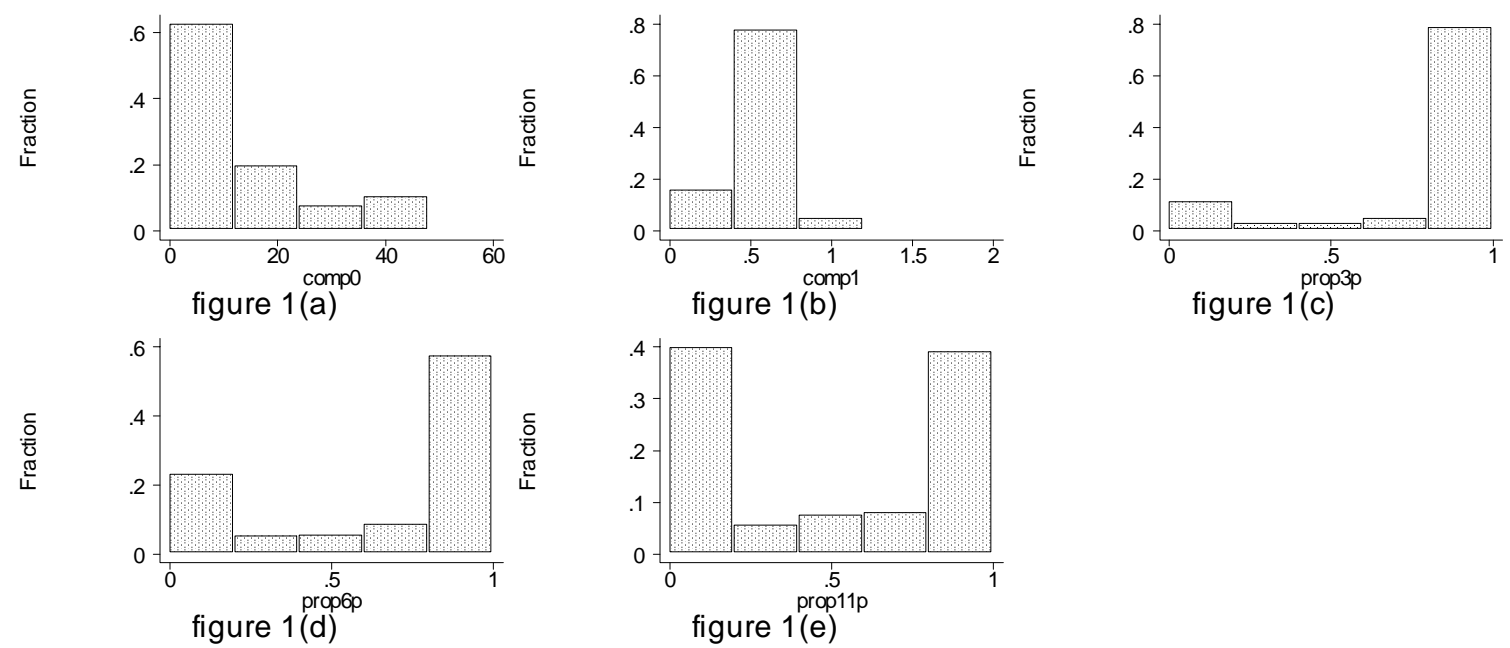

Figure 2: Time Trend in AMI death rates 1991-1999

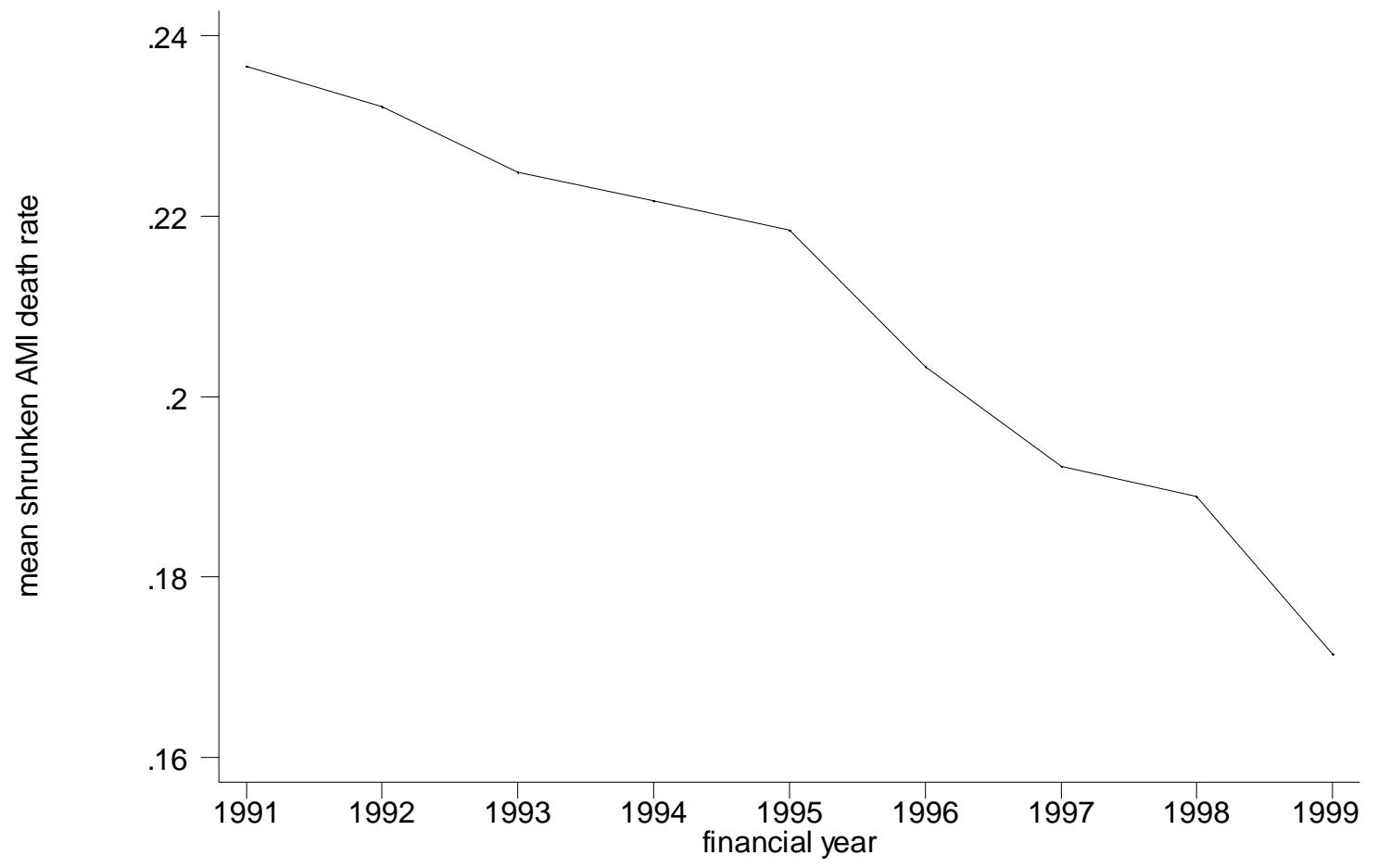


Figure 3: AMI death rates by three quantiles of competition measure $\mathrm{C} 1$

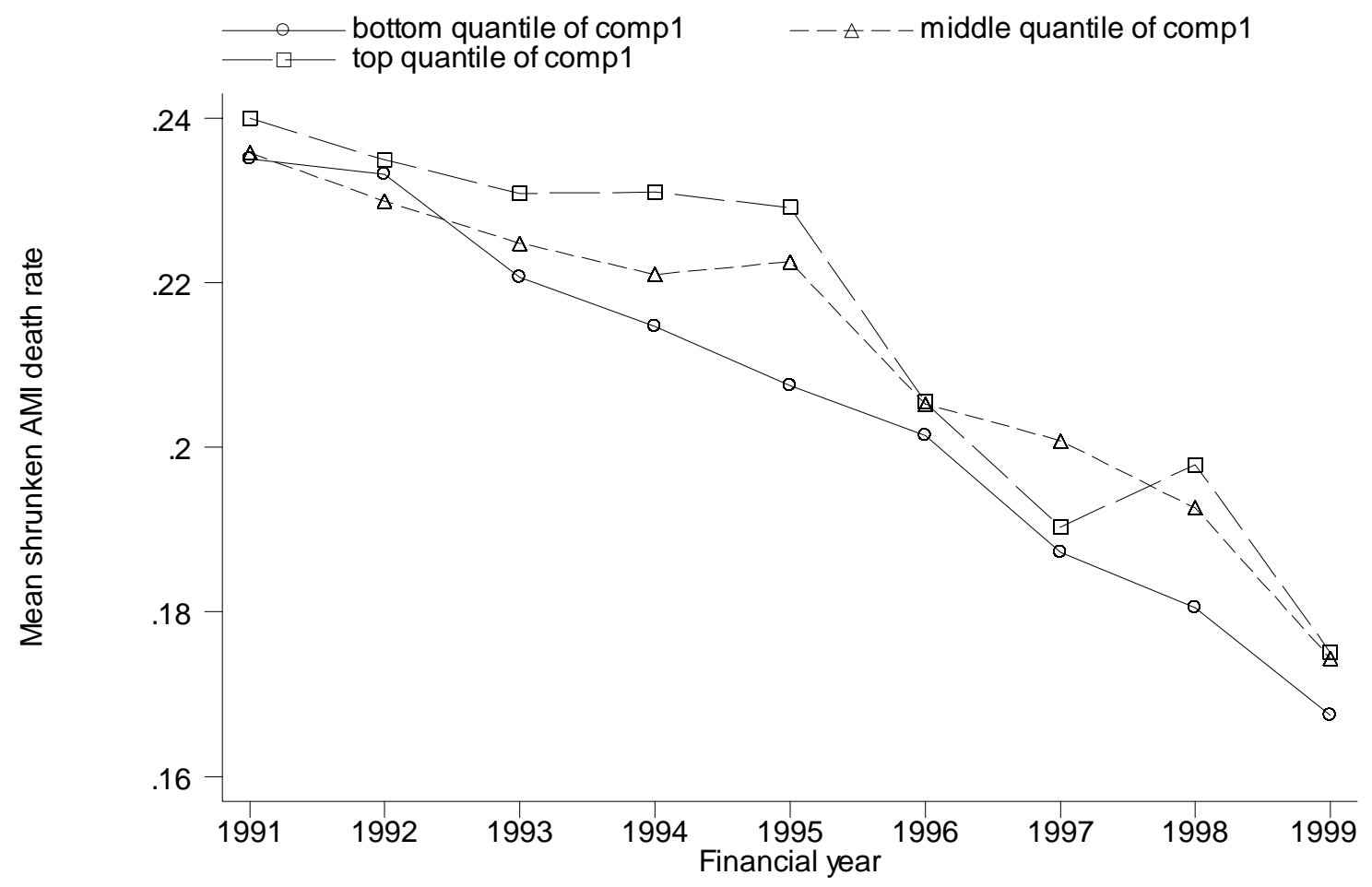


Figure 4: Coefficient estimates and 95\% confidence intervals for competition*time interactions from Table 3.
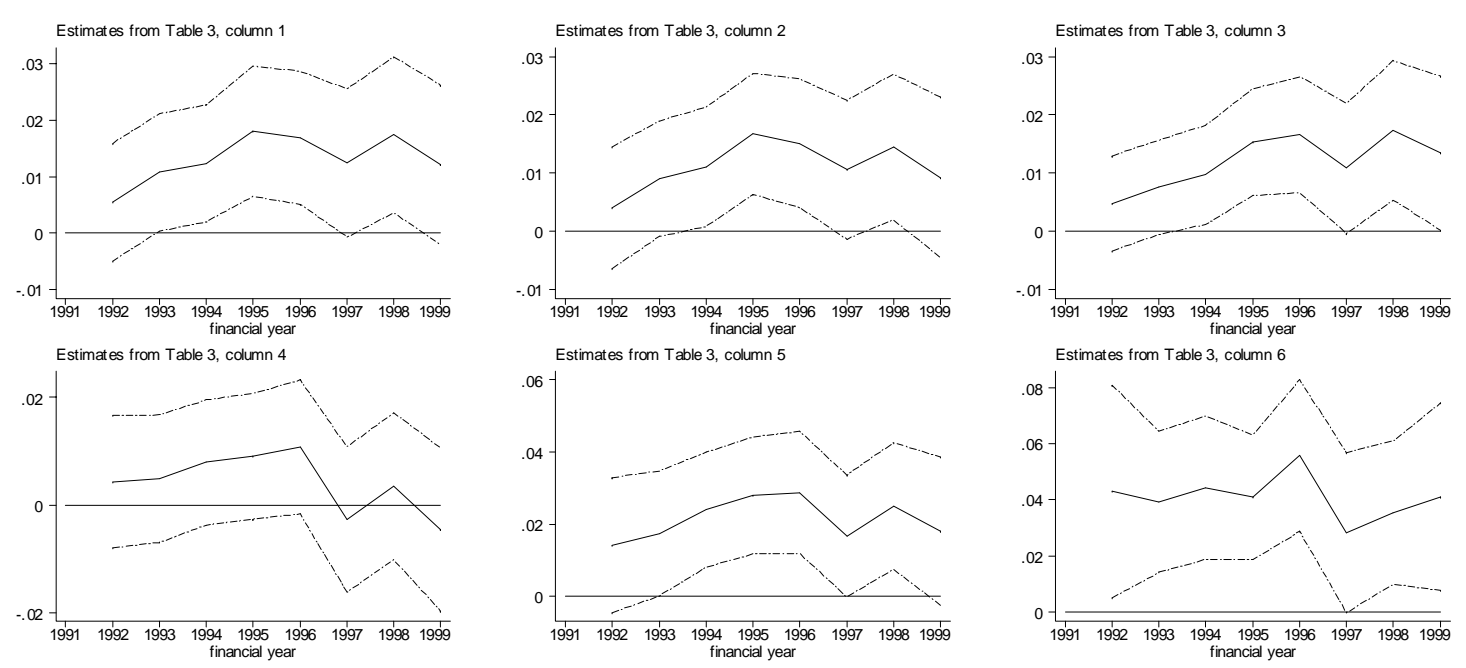
Table 1: Comparisons of hospital rankings: 1991, 1993 and 1995 and 1997. Outcome measure: Raw AMI emergency death rates 50+

\author{
Ranked in best $10 \%$ \\ (lowest mortality rate) \\ in 1991
}

Of the hospitals ranked in the best $10 \%$

in 1991:

1993

What percent were still ranked in the best $10 \%$ ?

$45 \%$

(lowest mortality rates)

What percent were ranked in the worst $10 \%$ ?

$5 \%$

(highest mortality rates)

Average difference in mortality rate from

$0.0734 * *$

all other hospitals

(0.0176)

(standard error of estimate)

1995

What percent were still ranked in the best $10 \%$ ?

$33.33 \%$

(lowest mortality rates)

What percent were ranked in the worst $10 \%$ ?

$14.29 \%$

(highest mortality rates)

Average difference in mortality rate from

0.0425

all other hospitals

(0.0271)

(standard error of estimate)

1997

What percent were still ranked in the best $10 \%$ ?

(lowest mortality rates)

What percent were ranked in the worst $10 \%$ ?

(highest mortality rates)

$0.0421 \sim$

Average difference in mortality rate from

(0.0238)

all other hospitals

(standard error of estimate)

$*$ significant at 5\%, **significant at $1 \%$ 
Table 2: Correlation between competition measures

\begin{tabular}{l|lllll} 
& comp0 & comp1 & prop3p & prop6p & prop11p \\
\hline comp0 & 1.0000 & & & & \\
comp1 & $0.3214^{*}$ & 1.0000 & & & \\
prop3p & $0.7245^{*}$ & 0.1000 & 1.0000 & & \\
prop6p & $0.8537^{*}$ & $0.2515^{*}$ & $0.7625^{*}$ & 1.0000 & \\
prop11p & $0.8186^{*}$ & $0.2455^{*}$ & $0.6590^{*}$ & $0.8563^{*}$ & 1.0000 \\
$*$ indicates $\mathrm{P} \leq 0.05$ & & & &
\end{tabular}


Table 3: Panel estimates of the impact of competition

\begin{tabular}{|c|c|c|c|c|c|c|}
\hline & \multicolumn{2}{|c|}{ Competition measure C1 } & \multirow{2}{*}{$\begin{array}{c}\text { No. of trusts in } \\
\text { service area } \\
\text { (3) }\end{array}$} & \multicolumn{3}{|c|}{ Competition measure C2 } \\
\hline & (1) & (2) & & (4) & (5) & (6) \\
\hline & $\begin{array}{l}\text { top } 2 \text { quantiles of } \\
\text { c1, all sample }\end{array}$ & $\begin{array}{l}\text { top } 2 \text { quantiles of } \mathrm{c} 1 \text {, } \\
\text { dropping monopolies } \\
\text { with small population }\end{array}$ & $\begin{array}{l}\text { monopoly trusts } \\
\text { versus all others }\end{array}$ & $\begin{array}{l}100 \% \text { of service } \\
\text { area pop can reach } 3 \\
\text { or more trusts }\end{array}$ & $\begin{array}{l}100 \% \text { of service } \\
\text { area pop can reach } 6 \\
\text { or more trusts }\end{array}$ & $\begin{array}{l}100 \% \text { of service } \\
\text { area pop can reach } \\
11 \text { or more trusts }\end{array}$ \\
\hline time & $\begin{array}{l}-0.0078 * * \\
(0.0007)\end{array}$ & $\begin{array}{c}-0.0076^{* *} \\
(0.0007)\end{array}$ & $\begin{array}{l}-0.0085^{* *} \\
(0.0008)\end{array}$ & $\begin{array}{c}-0.0067 * * \\
(0.0006)\end{array}$ & $\begin{array}{c}-0.0074 * * \\
(0.0005)\end{array}$ & $\begin{array}{c}-0.0071 * * \\
(0.0005)\end{array}$ \\
\hline comp*92 & $\begin{array}{c}0.0020 \\
(0.0050)\end{array}$ & $\begin{array}{l}0.0096 \sim \\
(0.0056)\end{array}$ & $\begin{array}{c}0.0048 \\
(0.0042)\end{array}$ & $\begin{array}{c}0.0043 \\
(0.0063)\end{array}$ & $\begin{array}{c}0.0142 \\
(0.0095)\end{array}$ & $\begin{array}{l}0.0430 * \\
(0.0194)\end{array}$ \\
\hline comp*93 & $\begin{array}{c}0.0069 \\
(0.0048)\end{array}$ & $\begin{array}{l}0.0152 * * \\
(0.0056)\end{array}$ & $\begin{array}{l}0.0076 \sim \\
(0.0041)\end{array}$ & $\begin{array}{c}0.0049 \\
(0.0060)\end{array}$ & $\begin{array}{l}0.0175 * \\
(0.0089)\end{array}$ & $\begin{array}{l}0.0392 * * \\
(0.0128)\end{array}$ \\
\hline comp*94 & $\begin{array}{l}0.0083 \sim \\
(0.0050)\end{array}$ & $\begin{array}{c}0.0175 * * \\
(0.0055)\end{array}$ & $\begin{array}{l}0.0097^{*} \\
(0.0044)\end{array}$ & $\begin{array}{c}0.0079 \\
(0.0059)\end{array}$ & $\begin{array}{c}0.0240 * * \\
(0.0081)\end{array}$ & $\begin{array}{l}0.0443 * * \\
(0.0131)\end{array}$ \\
\hline comp*95 & $\begin{array}{c}0.0135 * * \\
(0.0050)\end{array}$ & $\begin{array}{l}0.0239 * * \\
(0.0062)\end{array}$ & $\begin{array}{c}0.0153 * * \\
(0.0047)\end{array}$ & $\begin{array}{c}0.0090 \\
(0.0060)\end{array}$ & $\begin{array}{l}0.0280 * * \\
(0.0083)\end{array}$ & $\begin{array}{c}0.0409 * * \\
(0.0114)\end{array}$ \\
\hline comp*96 & $\begin{array}{l}0.0128^{*} \\
(0.0053)\end{array}$ & $\begin{array}{l}0.0219 * * \\
(0.0064)\end{array}$ & $\begin{array}{l}0.0166 * * \\
(0.0051)\end{array}$ & $\begin{array}{l}0.0108 \sim \\
(0.0064)\end{array}$ & $\begin{array}{l}0.0288 * * \\
(0.0087)\end{array}$ & $\begin{array}{l}0.0558 * * \\
(0.0138)\end{array}$ \\
\hline comp*97 & $\begin{array}{c}0.0083 \\
(0.0058)\end{array}$ & $\begin{array}{l}0.0175^{*} \\
(0.0070)\end{array}$ & $\begin{array}{l}0.0108 \sim \\
(0.0057)\end{array}$ & $\begin{array}{l}-0.0027 \\
(0.0069)\end{array}$ & $\begin{array}{l}0.0168 \sim \\
(0.0086)\end{array}$ & $\begin{array}{l}0.0283 \sim \\
(0.0146)\end{array}$ \\
\hline comp*98 & $\begin{array}{l}0.0121^{*} \\
(0.0060)\end{array}$ & $\begin{array}{l}0.0229 * * \\
(0.0074)\end{array}$ & $\begin{array}{l}0.0173 * * \\
(0.0061)\end{array}$ & $\begin{array}{c}0.0035 \\
(0.0070)\end{array}$ & $\begin{array}{l}0.0250 * * \\
(0.0090)\end{array}$ & $\begin{array}{l}0.0355 * * \\
(0.0131)\end{array}$ \\
\hline comp*99 & $\begin{array}{c}0.0079 \\
(0.0066)\end{array}$ & $\begin{array}{l}0.0166^{*} \\
(0.0075)\end{array}$ & $\begin{array}{l}0.0134^{*} \\
(0.0068)\end{array}$ & $\begin{array}{l}-0.0045 \\
(0.0077)\end{array}$ & $\begin{array}{l}0.0181 \sim \\
(0.0105)\end{array}$ & $\begin{array}{l}0.0410 * \\
(0.0171)\end{array}$ \\
\hline total adms & $\begin{array}{l}-2.79 \mathrm{e}-07 \\
(2.44 \mathrm{e}-07)\end{array}$ & $\begin{array}{c}-7.34 \mathrm{e}-07 * * \\
(2.32 \mathrm{e}-07)\end{array}$ & $\begin{array}{l}-3.42 \mathrm{e}-07 \\
(2.41 \mathrm{e}-07)\end{array}$ & $\begin{array}{l}-3.62 \mathrm{e}-07 \\
(2.42 \mathrm{e}-07)\end{array}$ & $\begin{array}{l}-2.77 \mathrm{e}-07 \\
(2.42 \mathrm{e}-07)\end{array}$ & $\begin{array}{l}-2.85 \mathrm{e}-07 \\
(2.40 \mathrm{e}-07)\end{array}$ \\
\hline Constant & $\begin{array}{l}0.4600 * * \\
(0.0266)\end{array}$ & $\begin{array}{l}0.3032 * * \\
(0.0124)\end{array}$ & $\begin{array}{l}0.4555 * * \\
(0.0277)\end{array}$ & $\begin{array}{l}1.0231 * * \\
(0.0057)\end{array}$ & $\begin{array}{l}0.4584 * * \\
(0.0273)\end{array}$ & $\begin{array}{l}0.4571 * * \\
(0.0278)\end{array}$ \\
\hline Observations & 1847 & 1710 & 1847 & 1847 & 1847 & 1847 \\
\hline No. of hosps & 226 & 210 & 226 & 226 & 226 & 226 \\
\hline R-squared & 0.75 & 0.70 & 0.75 & 0.75 & 0.75 & 0.75 \\
\hline
\end{tabular}

Robust standard errors in parentheses

$\sim$ significant at $10 \%$; * significant at $5 \%$; ** significant at $1 \%$ 
Table 4: Panel estimates of AMI death rates: robustness checks for case-mix

\begin{tabular}{|l|l|l|}
\hline & \multicolumn{1}{|c|}{$\begin{array}{c}\text { AMI death rate } \\
\text { males 50-69 }\end{array}$} & \multicolumn{1}{|c|}{$\begin{array}{c}\text { AMI death rate } \\
\text { females 50-69 }\end{array}$} \\
\hline time & $\begin{array}{l}-0.0058^{* *} \\
(0.0002)\end{array}$ & $\begin{array}{l}-0.0068^{* *} \\
(0.0002)\end{array}$ \\
comp*92 & -0.0018 & $0.0070 * *$ \\
& $(0.0016)$ & $(0.0017)$ \\
comp*93 & 0.0008 & -0.0015 \\
& $(0.0017)$ & $(0.0017)$ \\
comp*94 & $0.0058^{* *}$ & -0.0025 \\
& $(0.0017)$ & $(0.0018)$ \\
comp*95 & 0.0023 & $0.0049 * *$ \\
& $(0.0019)$ & $(0.0018)$ \\
comp*97 & $0.0052^{* *}$ & 0.0018 \\
& $(0.0019)$ & $(0.0020)$ \\
comp*98 & 0.0030 & -0.0011 \\
& $(0.0020)$ & $(0.0021)$ \\
comp*99 & $0.0040 \sim$ & 0.0015 \\
& $(0.0021)$ & $(0.0022)$ \\
total admissions & 0.0010 & -0.0018 \\
Constant & $(0.0023)$ & $(0.0024)$ \\
& $5.50 \mathrm{e}-08$ & 0.0000 \\
Observations & $(6.43 \mathrm{e}-08)$ & $(0.0000)$ \\
No. of hospitals & $0.1168 * *$ & $0.1652 * *$ \\
R-squared & $(0.0047)$ & $(0.0074)$ \\
\hline Robust standard & 1611 & 1591 \\
& 0.68 & 193 \\
& & 0.74 \\
\hline
\end{tabular}

Robust standard errors in parentheses

$\sim$ significant at $10 \% ; *$ significant at 5\%; ** significant at $1 \%$ 
Table 5: Panel estimates of death rates: examination of the impact of size.

\begin{tabular}{|c|c|c|c|c|c|c|c|c|}
\hline & $\begin{array}{c}\text { (1) } \\
\text { Below median } \\
\text { AMI spells }\end{array}$ & $\begin{array}{c}\text { (2) } \\
\text { Above median } \\
\text { AMI spells }\end{array}$ & $\begin{array}{c}\text { (3) } \\
\text { Below median } \\
\text { total spells }\end{array}$ & $\begin{array}{c}\text { (4) } \\
\text { Above median } \\
\text { total spells }\end{array}$ & $\begin{array}{c}(5) \\
\text { Below median } \\
\text { beds (1996) }\end{array}$ & $\begin{array}{c}(6) \\
\text { Above median } \\
\text { beds (1996) }\end{array}$ & $\begin{array}{c}(7) \\
\text { Below median } \\
\text { (total adms/no. } \\
\text { doctors) }\end{array}$ & $\begin{array}{c}\text { (8) } \\
\text { Above median } \\
\text { (total adms/no. } \\
\text { doctors) }\end{array}$ \\
\hline time & $\begin{array}{c}-0.0056 * * \\
(0.0012)\end{array}$ & $\begin{array}{c}-0.0093 * * \\
(0.0009)\end{array}$ & $\begin{array}{c}-0.0071 * * \\
(0.0012)\end{array}$ & $\begin{array}{c}-0.0083 * * \\
(0.0008)\end{array}$ & $\begin{array}{c}-0.0072 * * \\
(0.0011)\end{array}$ & $\begin{array}{c}-0.0084 * * \\
(0.0009)\end{array}$ & $\begin{array}{c}-0.0073 * * \\
(0.0010)\end{array}$ & $\begin{array}{c}-0.0083^{*} * \\
(0.0009)\end{array}$ \\
\hline comp $* 92$ & $\begin{array}{c}0.0109 \\
(0.0087)\end{array}$ & $\begin{array}{l}-0.0048 \\
(0.0060)\end{array}$ & $\begin{array}{c}0.0055 \\
(0.0087)\end{array}$ & $\begin{array}{c}0.0025 \\
(0.0066)\end{array}$ & $\begin{array}{c}0.0092 \\
(0.0085)\end{array}$ & $\begin{array}{c}-0.0013 \\
(0.0066)\end{array}$ & $\begin{array}{c}0.0093 \\
(0.0077)\end{array}$ & $\begin{array}{l}-0.0024 \\
(0.0071)\end{array}$ \\
\hline comp*93 & $\begin{array}{c}0.0105 \\
(0.0083)\end{array}$ & $\begin{array}{c}0.0045 \\
(0.0057)\end{array}$ & $\begin{array}{c}0.0098 \\
(0.0080)\end{array}$ & $\begin{array}{c}0.0076 \\
(0.0066)\end{array}$ & $\begin{array}{c}0.0118 \\
(0.0077)\end{array}$ & $\begin{array}{c}0.0054 \\
(0.0067)\end{array}$ & $\begin{array}{l}0.0128 \sim \\
(0.0072)\end{array}$ & $\begin{array}{c}0.0040 \\
(0.0068)\end{array}$ \\
\hline comp*94 & $\begin{array}{l}0.0165 \sim \\
(0.0088)\end{array}$ & $\begin{array}{c}0.0006 \\
(0.0057)\end{array}$ & $\begin{array}{c}0.0103 \\
(0.0089)\end{array}$ & $\begin{array}{l}0.0110 \sim \\
(0.0062)\end{array}$ & $\begin{array}{c}0.0128 \\
(0.0084)\end{array}$ & $\begin{array}{c}0.0086 \\
(0.0064)\end{array}$ & $\begin{array}{l}0.0168 * \\
(0.0073)\end{array}$ & $\begin{array}{c}0.0036 \\
(0.0075)\end{array}$ \\
\hline comp*95 & $\begin{array}{l}0.0182 * \\
(0.0090)\end{array}$ & $\begin{array}{c}0.0096 \\
(0.0061)\end{array}$ & $\begin{array}{l}0.0166 \sim \\
(0.0090)\end{array}$ & $\begin{array}{l}0.0163 * \\
(0.0065)\end{array}$ & $\begin{array}{c}0.0175^{*} \\
(0.0085)\end{array}$ & $\begin{array}{l}0.0145^{*} \\
(0.0067)\end{array}$ & $\begin{array}{c}0.0245^{* * *} \\
(0.0078)\end{array}$ & $\begin{array}{c}0.0065 \\
(0.0069)\end{array}$ \\
\hline comp*96 & $\begin{array}{l}0.0172 \sim \\
(0.0098)\end{array}$ & $\begin{array}{c}0.0068 \\
(0.0064)\end{array}$ & $\begin{array}{l}0.0187 \sim \\
(0.0096)\end{array}$ & $\begin{array}{l}0.0118 \sim \\
(0.0071)\end{array}$ & $\begin{array}{l}0.0153 \sim \\
(0.0091)\end{array}$ & $\begin{array}{l}0.0133 \sim \\
(0.0071)\end{array}$ & $\begin{array}{c}0.0255^{* * *} \\
(0.0083)\end{array}$ & $\begin{array}{c}0.0020 \\
(0.0075)\end{array}$ \\
\hline comp*97 & $\begin{array}{c}0.0118 \\
(0.0105)\end{array}$ & $\begin{array}{c}0.0014 \\
(0.0071)\end{array}$ & $\begin{array}{c}0.0156 \\
(0.0103)\end{array}$ & $\begin{array}{c}0.0056 \\
(0.0076)\end{array}$ & $\begin{array}{c}0.0154 \\
(0.0098)\end{array}$ & $\begin{array}{c}0.0043 \\
(0.0076)\end{array}$ & $\begin{array}{l}0.0154 \sim \\
(0.0091)\end{array}$ & $\begin{array}{c}0.0037 \\
(0.0081)\end{array}$ \\
\hline comp*98 & $\begin{array}{c}0.0127 \\
(0.0111)\end{array}$ & $\begin{array}{c}0.0073 \\
(0.0076)\end{array}$ & $\begin{array}{l}0.0215 \sim \\
(0.0112)\end{array}$ & $\begin{array}{c}0.0092 \\
(0.0078)\end{array}$ & $\begin{array}{l}0.0208^{*} \\
(0.0105)\end{array}$ & $\begin{array}{c}0.0072 \\
(0.0080)\end{array}$ & $\begin{array}{l}0.0213 * \\
(0.0094)\end{array}$ & $\begin{array}{c}0.0047 \\
(0.0089)\end{array}$ \\
\hline comp*99 & $\begin{array}{c}0.0073 \\
(0.0123)\end{array}$ & $\begin{array}{c}0.0011 \\
(0.0086)\end{array}$ & $\begin{array}{c}0.0176 \\
(0.0124)\end{array}$ & $\begin{array}{c}0.0045 \\
(0.0086)\end{array}$ & $\begin{array}{c}0.0111 \\
(0.0117)\end{array}$ & $\begin{array}{c}0.0056 \\
(0.0089)\end{array}$ & $\begin{array}{c}0.0156 \\
(0.0106)\end{array}$ & $\begin{array}{l}-0.0003 \\
(0.0093)\end{array}$ \\
\hline total admissions & $\begin{array}{l}-3.12 \mathrm{e}-07 \\
(4.10 \mathrm{e}-07)\end{array}$ & $\begin{array}{c}2.01 \mathrm{e}-08 \\
(3.40 \mathrm{e}-07)\end{array}$ & $\begin{array}{l}-5.55 e-07 \\
(4.76 e-07)\end{array}$ & $\begin{array}{l}-1.35 e-07 \\
(3.01 e-07)\end{array}$ & $\begin{array}{l}-3.74 \mathrm{e}-08 \\
(4.39 \mathrm{e}-07)\end{array}$ & $\begin{array}{l}-2.16 \mathrm{e}-07 \\
(3.14 \mathrm{e}-07)\end{array}$ & $\begin{array}{l}-1.46 e-07 \\
(3.76 e-07)\end{array}$ & $\begin{array}{l}-2.89 \mathrm{e}-07 \\
(3.38 \mathrm{e}-07)\end{array}$ \\
\hline Constant & $\begin{array}{c}0.2231 * * \\
(0.0362)\end{array}$ & $\begin{array}{c}0.2855^{* *} \\
(0.0146)\end{array}$ & $\begin{array}{c}0.3220 * * \\
(0.0223)\end{array}$ & $\begin{array}{c}0.2381 * * \\
(0.0235)\end{array}$ & $\begin{array}{c}0.4558 * * \\
(0.0285)\end{array}$ & $\begin{array}{c}0.3408 * * \\
(0.0238)\end{array}$ & $\begin{array}{c}0.4570 * * \\
(0.0281)\end{array}$ & $\begin{array}{c}0.2721 * * \\
(0.0243)\end{array}$ \\
\hline Observations & 720 & 990 & 657 & 1053 & 720 & 982 & 818 & 892 \\
\hline No. of hospitals & 95 & 115 & 89 & 121 & 94 & 115 & 103 & 107 \\
\hline R-squared & 0.80 & 0.65 & 0.82 & 0.60 & 0.81 & 0.62 & 0.77 & 0.75 \\
\hline
\end{tabular}

Robust standard errors in parentheses

$\sim$ significant at $10 \% ; *$ significant at $5 \%$; * significant at $1 \%$ 
